\title{
The Adjudicated Case Study Method, Part 2: Editor's Introduction
}

\section{DANIEL B. FISHMAN, ${ }^{\mathrm{a}, \mathrm{b}}$}

\author{
${ }^{a}$ Graduate School of Applied and Professional Psychology, Rutgers University-New Brunswick \\ ${ }^{\mathrm{b}}$ Correspondence regarding this article should be sent to: Daniel B. Fishman, 43 Clarewood Lane, Oakland, CA \\ 94618. \\ Email: dfishman.rutgers@gmail.com
}

\begin{abstract}
This article introduces readers to the present PCSP issue on the "adjudicated case study method." This method employs concepts from the law for evaluating qualitative information to determine the truth of statements about human psychology and behavior, including causal statements about psychotherapy outcome. Two models of the adjudicated case study method, which were originally presented in PCSP in 2011, are covered: Ronald Miller's "Panels of Psychological Inquiry" (PPI), and Arthur Bohart's "Research Jury Method." The issue concludes with a Commentary by Robert Elliott, Susan Stephen, and Anna Robinson.
\end{abstract}

Key words: adjudicated case study method; Panels of Psychological Inquiry; Research Jury Method; case study; clinical case study

This is the second PCSP issue devoted to the "Adjudicated Case Study Method," which is a qualitative case study method for assessing causality and outcome in psychotherapy. Here is how I introduced the first issue on this topic in 2011:

This PCSP journal has promoted the development and publication of systematic, single case studies of psychotherapy typically written by the therapist himself or herself. In this design, there is a need for a critical evaluation of the therapist's selection, interpretation, and narrative integration of the "raw data" interactions between the therapist and client, as represented, for example, by videotapes of all the therapy sessions (Messer, 2007; McLeod, 2010). This critical evaluation includes the therapist's own critical perspective, frequently facilitated by clinical case supervision, which should be clear in the case narrative. In addition, there should be provided perspectives that are independent of the therapist's interpretations. Typically, in past $P C S P$ case studies, these independent perspectives include: (a) extensive quotes from therapy transcripts; (b) standardized, quantitative process and outcome data; (c) standardized qualitative measures, such as Lleweln's (1988) "Helpful Aspects of Therapy" (HAT) form; and (d) critical discussions of the final case study by outside commentators that are published simultaneously with the case study.

The current issue of the PCSP journal presents an additional method to critically evaluate the knowledge claims in a target case study via informed, independent perspectives. This method, whose concepts and procedures are drawn from the legal system, has been called the "quasi-judicial method" (Bromley, 1986) and the "adjudicated case study method" (Stephen \& Elliott, 2011). These concepts and procedures include an adversarial model of 
truth with (a) its systematic use of advocates (such as prosecutors) and critics (such as defense lawyers); (b) its use of the cross-examination of relevant actors and witnesses; and (c) its use of panels of jurors or judges, who come to a final decision on the truth of knowledge claims, sometimes taking into account the views of the advocates, critics, and witnesses (Fishman, 2011, p. 1-2).

\section{RONALD MILLER'S “PANELS OF PSYCHOLOGICAL INQUIRY" (PPI): THE CASE OF "RONAN"}

\section{The Method}

The present issue contains the two models of adjudicated case studies that were published in the first issue (Fishman, 2011). First Ronald Miller and colleagues (Miller et al., 2021) present a case example of his "Panels of Psychological Inquiry" (PPI) model (Miller, 2004, 2011), which parallels the process of a court hearing in detail. Specifically, in this issue Miller applies his PPI model to the case of "Ronan," a two year old boy who was diagnosed with moderate to severe autism spectrum disorder (ASD), and treated in an Early Intervention, Therapeutic Daycare Center (hereafter called "The Daycare Center"), a specialized childcare facility for children with autism.

The Daycare Center provides a form of "DIR/Floortime" treatment, which focuses on the social relationship between adult caregiver and child, with learning opportunities through social interaction. This was a controversial case since the treatment employed challenged the prevailing wisdom in the ASD field: the accepted therapy model for autism of Applied Behavior Analysis. In the PPI, Miller brought together the following individuals: (a) the clinician who provided the therapy and her supervisor as "witnesses" to how Ronan originally presented, the nature of his therapy, and the outcome of his therapy; (b) an "advocate" for the value of the treatment; (c) an opposing "critic" of its value; and (d) three judges who evaluated the evidence and testimony of individuals (a) - (c). There were four truth claims that the PPI sought to answer, as follows

Claim \#1: At the time of treatment, Ronan had Autism Spectrum Disorder (ASD) (p. 146)....

Claim \#2: The therapist implemented a relationship-based model of therapy in the context of the Center's therapeutic milieu (p. 151)....

Claim \#3: Kristin's application of relationship-based therapy, in the context of the Daycare Center's therapeutic milieu, improved Ronan's outcomes (p. 159). ...

Claim \#4: It is likely that there is at least a subset of children with moderate to severe Autism Spectrum Disorder for whom this treatment is likely to be helpful"' (p. 164).

\section{The Clinical Case and Setting}

Ronan was born to drug-addicted parents who had difficulty meeting his needs. At 20 months old, he went into custody of the Child Protective Services Department of the State of 
Vermont, and he then began to live with his aunt, "Annette." In her care, he was evaluated by a Child Development Clinic to address his significant developmental delays. He was diagnosed as being on the autistic spectrum because of his deficits in social communication and social interaction; and his restricted, repetitive, and stereotyped patterns of behavior, interests, and activities. Based on this diagnosis, at 25 months Ronan started at the Daycare Center.

As part of her practicum and internship in a clinical psychology MA training program, Kristen Mount was assigned to the Daycare Center, and Ronan was one of her clients. Her work with Ronan was supervised by the Daycare Center's founder and director, Michelle Fouts, a licensed clinical psychologist. Mount's masters thesis was a detailed systematic case study of her work with Ronan. An edited version of her thesis (Mount, 2021) was an important component of Miller's PPI about Ronan, and this edited version can be found in Appendix A to Miller et al.'s article in this issue

The Early Intervention Center that Ronan attended is an intensive childcare program with a high adult to child ratio. While it does use some behavioral approaches based on Applied Behavior Analysis principles, it is primarily organized around the principles of Greenspan's (2009) “Developmental, Individual-differences, Relationship-based” (“DIR”) model. This approach emphasizes a parent spending time and playing at the child's level on the floor, called "Floortime-Based Play," or just "Floortime." Specifically, Greenspan's DIR/Floortime model (2021) is based on a number of core principles, including:

- $\quad$ Floortime ${ }^{\mathrm{TM}}$ sessions: These sessions focus on encouraging the child's initiative and purposeful behavior, deepening engagement, lengthening mutual attention, and developing symbolic capacities through pretend play and conversations, always following the child's lead.

- Semi-structured problem-solving: These sessions involve setting up meaningful and relevant challenges to be solved in order to teach a child something new. The challenges can be set up as selected learning activities that are meaningful and relevant to the child's experiences.

- Motor, sensory, sensory integration, visual-spatial, and perceptual motor activities: These activities are geared to the child's individual differences and regulatory patterns, building basic processing capacities and providing the support to help children become engaged, attentive, and regulated during interactions with others.

- $\quad$ Peer play with one other child: Peer play should be started once a child is fully engaged and interactive, with parents providing mediation when necessary to encourage engagement and interaction between the children.

In her thesis, Mount describes the Daycare Center as follows:

The setting of the Center is in a converted house. The room design and toy selection was very deliberate. There are few distractions on the walls. Toys are not electronic or overstimulating, and are put behind a closed door when not in use. This reduces distractions, but also encourages communication for when a child wants to take something out. Symbolic play is encouraged with the use of puppets, dolls, stuffed animals, and costumes. There is a 
rhythm to the day, but not a set schedule. The house is set on the top of a hill with a spacious meadow in the front and woods in the rear. Nearby is a dirt road leading to a river. Within a day, outdoor play, nature walks, or running through the field to climb on hay bales may ensue, depending on the needs and expressed desires of the children (Mount, 2021, p. 182).

\section{ARTHUR BOHART'S "RESEARCH JURY METHOD"}

\section{The Method}

In the second article in this issue, Arthur Bohart and his students, Lindsey Shenefiel and Marco Alejandro, review and analyze the case study of "Carl" and "Sandra." The couple, who were in marital conflict, were seen in 10 videotaped sessions of emotion-focused couple therapy (Johnson, 2004). The sessions were part of a published training case by therapist Rebecca Jorgensen (httpsth://drrebeccajorgensen.com/). Bohart, Shenefiel, and Alejandro (2021) analyzed the case of Carl and Sandra using Bohart's Research Jury Method (Bohart, Berry, \& Wicks, 2011; Bohart \& Humphreys, 2000; Bohart, Tallman, Byock, \& Mackrill, 2011). Specifically, Bohart, Shenefiel, and Alejandro (2021) assumed the role of a three-judge jury in evaluating a number of claims about Carl and Sandra's therapy, such as whether they improved over the course of the treatment, and if so, whether the therapy was a causal agent in that change. An important focus is on what is considered evidence, in both scientific and judicial contexts, and how to use the qualitative information from the videos of Carl and Sandra's therapy in reaching epistemologically sound conclusions about the therapy.

\section{The Clinical Case and Setting}

Bohart et al. describe the reasons why Carl and Sandra first entered therapy:

One of the major issues as presented by them ... is where they live. [Carl and Sandra] are currently living in a recreational vehicle (RV) [in St. Louis] in an area where they do not feel safe. Sandra, in particular, hates this. Sandra owns an inn in Arkansas. ... Carl does not want anything to do with the inn. Sandra does not want anything to do with Carl's house in St. Louis.

The second major issue is that Sandra does not feel that Carl sufficiently takes her wishes, needs, and safety into account.

The third issue is that, from Carl's point of view, he feels criticized, misunderstood, and that he cannot win....

One last note about the case: Both members of the couple are in an alcoholism recovery program ... [and] both have previously been in therapy (Bohart et al., 2021, p. 218).interaction cycles

The Emotion-Focused Couple therapy that Jorgensen employed in working with Carl and Sandra provided treatment based on the notion that 
couples are caught in dysfunctional interaction cycles, or patterns, that cause their problems. These dysfunctional interaction cycles are based on underlying attachment needs that are being frustrated or denied. The goal of the therapist is to empathically support the couple while helping them become aware of the pattern and of their underlying attachment needs (Bohart et al., 2021, p. 214).

\section{COMMENTARY}

The issue concludes with a Commentary by Robert Elliott, Susan Stephen, and Anna Robinson (2021). This article begins with a review of the progress made in the adjudicated case study method since 2011 in terms of Miller's PPI Method, Bohart's Research Jury Method, and Elliott's own version, the "Hermeneutic Single Case Efficacy Design" (HSCED). The Commentary ends with a discussion of the value of the method and its prospects for further evolution across the variety of its versions.

\section{REFERENCES}

Bohart, A. C., Berry, M., \& Wicks, C. (2011). Developing a systematic framework for utilizing discrete types of qualitative data as therapy research evidence. Pragmatic Case Studies in Psychotherapy, 7 (1), Article 9, 145-155. Available: https://pcsp.libraries.rutgers.edu/

Bohart, A. C., \& Humphreys, C. (2000, June). A qualitative "adjudicational" model for assessing psychotherapy outcome. Paper presented at the meeting of the International Society for Psychotherapy Research, Chicago, Illinois.

Bohart, A.C., Shenefiel, L., \& Alejandro, M. (2021). What can we learn about therapeutic change from case history data? The case of "Carl" and "Sandra." Pragmatic Case Studies in Psychotherapy, 17 (2), Article 3, 210-234. Available: https://pcsp.libraries.rutgers.edu/

Bohart, A. C., Tallman, K., Byock, G., \& Mackrill, T. (2011). The "Research Jury Method": The application of the jury trial model to evaluating the validity of descriptive and causal statements about psychotherapy process and outcome. Pragmatic Case Studies in Psychotherapy, 7 (1), Article 8, 101-144. Available: https://pcsp.libraries.rutgers.edu/

Bromley, D. B. (1986). The case-study method in psychology and related disciplines. Chichester: John Wiley \& Sons Ltd.

Elliott, R., Stephen, S., \& Robinson, A. (2021). Commentary-Extending the Boundaries of Systematic Case Study Research: Conceptual and Methodological Issues. Pragmatic Case Studies in Psychotherapy, 17 (2), Article 4, 235-254. Available: https://pcsp.libraries.rutgers.edu/

Fishman, D.B. (2011). A promising strategy for critically evaluating case studies: Introduction to an issue on the adjudicated case study method. Pragmatic Case Studies in Psychotherapy, 7(1), Article 1, 1-5. Available: https://pcsp.libraries.rutgers.edu/

Johnson, S. (2004). The practice of emotionally focused couple therapy: Creating connection. New York: Routledge.

Llewelyn, S. (1988). Psychological therapy as viewed by clients and therapists. British Journal of Clinical Psychology, 27, 223-238

McLeod, J. (2010). Case study research in counselling and psychotherapy. London: Sage. 
Messer, S.B. (2007). Psychoanalytic case studies and the pragmatic case study method. Pragmatic Case Studies In Psychotherapy, 3(1), Article 4, 55-58. Available: https://pcsp.libraries.rutgers.edu/

Miller, R.B. (2004). Facing human suffering. Psychology and psychotherapy as moral engagement. Washington, DC: American Psychological Association.

Miller, R.B. (2011). Real Clinical Trials $\left(\mathrm{RCT}^{1}\right)$ - Panels of Psychological Inquiry for transforming anecdotal data into clinical facts and validated judgments: Introduction to a pilot test with the case of "Anna." Pragmatic Case Studies in Psychotherapy, 7(1), Article 2, 6-36. Available: https://pcsp.libraries.rutgers.edu/

Miller, R.B., Ashley, B., Mount, K., Tuepker, S., Powell, T., O’Leary, D., Fouts, M., Allshouse. K., Rusczek, J., HenneBarrows, K., \& Dombroski, A. (2021). Further developments in the Panel of Psychological Inquiry Method of case study research: The case of "Ronan." Pragmatic Case Studies in Psychotherapy, 17 (2), Article 2, 129-209. Available: https://pcsp.libraries.rutgers.edu/

Mount, K. (2021). The Intricate Connections between Autism and Trauma: A case study. Appendix A in R.B. Miller et al., Further developments in the Panel of Psychological Inquiry Method of case study research: The case of "Ronan." Pragmatic Case Studies in Psychotherapy, 17 (2), Article 2, 129-209. Available: https://pcsp.libraries.rutgers.edu/

Stephen, S., \& Elliott, R. (2011). Developing the adjudicated case study method Pragmatic Case Studies in Psychotherapy, 7(1), Article 12, 230-241. Available: https://pcsp.libraries.rutgers.edu/

Stephen, S., Elliott, R., Robinson, A. (2021). Extending the boundaries of systematic case study research: Conceptual and methodological issues. Pragmatic Case Studies in Psychotherapy, 17(1), Article 4, 235-254. Available: https://pcsp.libraries.rutgers.edu/ 